\title{
Forecasting the Number of Tuberculosis (TBC) Using Fuzzy Prey Predator
}

\author{
Subaidah $^{1}$, Putri Ukhrowi ${ }^{2}$, Achmad Alam ${ }^{3}$, Tony Yulianto ${ }^{4}$ \\ \{subaidah@gmail.com ${ }^{1}$, poalayyasyi@gmail.com ${ }^{2}$, alam1018@gmail.com ${ }^{3}$ \} \\ 1,2,3,4 Mathematics Department, Mathemathics and Science Faculty, Islamic University of Madura, \\ Pamekasan, Madura, Indonesia
}

\begin{abstract}
Tuberculosis (TB or TB) is an infectious disease caused by the bacterium Mycobacterium tuberculosis. Tuberculosis (TB) is still a major health problem in the world, so from this it is necessary to forecast to determine the increase in the number of TB diseases, and later can be taken in prevention. This study uses the Fuzzy prey predator method. The data source used is data on TB patients at Batumarmar Health Center. From the results of this study, it was found that the population of Prey and Predator was sought for stability, so that after applying the fuzzy prey predator model, convergent results were obtained. Prey population and Predator population decreased for one month, afterwards covergen.
\end{abstract}

Keywords: Tuberculosis (TBC), forecasting, fuzzy prey predator.

\section{Introduction}

Tuberculosis (TB or TB) is an infectious disease caused by the bacterium Mycobacterium tuberculosis. Tuberculosis (TB) is still a major health problem in the world. This causes health problems in millions of people each year and becomes ranked second as the main cause of death from disease infections worldwide after the Human Immunodeficiency Virus (HIV). In 2012, there were 8.6 million people worldwide affected by TB and 1.3 million people died from this disease (including 320,000 deaths of people with HIV). Most of the tuberculosis (TB) germs attack adults in productive age. However, in the group of children one million children (0-14 years old) were sick because TB and 170,000 children died of TB in 2015 [1]. According to WHO data in 2011 states that Indonesia is ranked fourth in the world with the most TB sufferers after India, China and southern Africa.

The World Health Organization (WHO) states that, in 1999 in Indonesia every year 583 new cases occurred with the death of 130 patients with positive tuberculosis in their phlegm. Whereas according to the results of the Kusnindar research in 1990, the number of deaths caused by tuberculosis was estimated at 105,952 per year. The most increase in tuberculosis cases occurs in groups of people with weak socio-economic conditions, influenced by endurance, nutritional status, individual personal hygiene and density of housing [2]

TB is one of the most infectious diseases found in East Java, in 2015 East Java occupied the second highest case of pulmonary TB patients after West Java, which amounted to 23,183 patients [3]. TB sufferers in the pamekasan city are ranked fifth, under Sumenep Regency, Lumajang, Malang City and Jember [4]. Based on data from the Pameksan District Health Office, there were 1,110 in 2014 [5].

Many methods can predict the number of TB disease, one method that can be used is fuzzy prey predator. In this method, fuzzy set theory is used to create a model that studies the 
interaction between prey (prey) and predator (predator) characters in the form of ordinary differential equations that characterize classical deterministic models [6].The prey in this study was humans, while the predators were tuberculosis. Then the decomposition of predator-prey models that represent the interaction between prey (prey) and predator (predator) using a fuzzy rule-based system. Next, it is proposed the deterministic classical model given by the system of ordinary differential equations, for example there is a predatorprey system whose solution coincides with the fuzzy model. By adjusting the parameters of the differential equation from the fuzzy model obtained, so that system stability analysis can be carried out [6].

Based on previous research entitled "Predator Prey Model with Early Fuzzy Populations" the results of his research propose a new way to study prey-prey population models, which take into account the uncertainties that arise when determining predator and prey initial populations. By using the concept of fuzzy interval interactivity, the Runge-Kutta Method, to estimate the number of predators and prey over time. In research entitled "PredatorPrey Fuzzy Delay System. Theory of the Existence of the Theorem and Oscillation Solution "succeeded in proving the existence and uniqueness of FDPP solutions at intervals [0, interval].

Based on the research, no one has examined the problem of forecasting the number of tuberculosis. For this reason, in this study the authors are interested in using Fuzzy Prey Predator in a study entitled "Forecasting the number of TB diseases using the Fuzzy Prey Predator method" So that this title is expected to be able to determine the amount of TB disease increase.

\section{Definition of fuzzy logic}

Fuzzy logic was first introduced by Prof. Lotfi A. Zadeh in 1965. Classic and Fuzzy Sets Basically, fuzzy set theory is an extension of classical set theory. In crisp, the value of membership of the item is written with $\mu \mathrm{A}$ [x], has 2 possibilities, namely [7]. One, which means that an item becomes a member in a set, or Zero, which means that the item is not a member of a set.

\section{Prey predator}

The prey predator system with two predators can be seen in the following differential equation:

$$
\begin{aligned}
& \frac{d N}{d t}=r N\left(1-\frac{N}{K}\right)-\alpha P N-\varphi Q N \\
& \frac{d P}{d t}=-c P+\beta N P \\
& \frac{d Q}{d t}=-e Q+\gamma N Q
\end{aligned}
$$

$\mathrm{K}=$ the carrying capacity of the prey environment

$\mathrm{r}=$ prey growth rate

$\mathrm{c}=$ first predator growth rate

$\mathrm{e}=$ the growth rate of the second predator

$\beta=$ first predator rate of prey

$\gamma=$ second predator contraction rate to prey

$\alpha=$ prey contraction rate of the first predator

$\varphi=$ prey contraction rate of the second predator 


\section{Equilibrium point}

Definition 2.1 [6]

A point $x_{e}$ is said to be the equilibrium point of equation

$$
\begin{aligned}
& \dot{x}_{1}(t)=x_{1}(t)\left(\mu_{1}-r_{12} x_{2}(t)\right) \\
& \dot{x}_{2}(t)=x_{2}(t)\left(\mu_{2}-r_{21} x_{1}(t)\right)
\end{aligned}
$$

at time $t_{0}$, if for each $t \geq t_{0}$, then the result $f\left(x_{e}\right)=0$.

From this definition it gives the meaning that the equilibrium point $x_{e}$ is a constant solution of equation

$$
\begin{aligned}
& \dot{x}_{1}(t)=x_{1}(t)\left(\mu_{1}-r_{12} x_{2}(t)\right) \\
& \dot{x}_{2}(t)=x_{2}(t)\left(\mu_{2}-r_{21} x_{1}(t)\right)
\end{aligned}
$$

when $f\left(x_{e}\right)=0$ so that $\boldsymbol{x}^{\prime}(t)=0$ at that point.

\section{Proposition 2.1 [6]}

If an $x_{e}$ equilibrium point is stable, the fuzzy is also stable.

\section{System linearization}

Linearizasion system of a system of nonlinear differential equations using a Taylor series.

Given a dynamic system as follows:

$$
\begin{aligned}
& \dot{x_{1}}=f_{1}\left(x_{1}, x_{2}\right) \\
& \dot{x}_{2}=f_{2}\left(x_{1}, x_{2}\right)
\end{aligned}
$$

Suppose the function component $f_{i}\left(x_{1}, x_{2}\right), i=1,2$, has a continuous derivative around the equilibrium point $\left(c_{1}, c_{2}\right)$. So that from equation (2.) can be written in the form of a matrix as follows:

$$
\left[\begin{array}{l}
\dot{x_{1}} \\
\dot{x_{2}}
\end{array}\right]=\left[\begin{array}{ll}
\left.\frac{\partial f_{1}}{\partial x_{1}}\right|_{\left(c_{1}, c_{2}\right)} & \left.\frac{\partial f_{1}}{\partial x_{2}}\right|_{\left(c_{1}, c_{2}\right)} \\
\left.\frac{\partial f_{2}}{\partial x_{1}}\right|_{\left(c_{1}, c_{2}\right)} & \left.\frac{\partial f_{2}}{\partial x_{2}}\right|_{\left(c_{1}, c_{2}\right)}
\end{array}\right]\left[\begin{array}{l}
y_{1} \\
y_{2}
\end{array}\right]
$$

\section{Stability}

\section{Definition 2.1 [8]}

Suppose matrix $(n \times n)$. A nonzero vector $v$ in $R^{n}$ is called the eigenvector of $\mathrm{A}$, if for a scalar $\lambda$ is called the eigenvalue of matrix $A$, then it applies:

$$
A v=\lambda v
$$

The vector is called the eigenvector of $A$ when it corresponds to the eigenvalue $\lambda$.

To find the eigenvalue of the matrix A equation (3) can be written as follows:

$$
(A-I \lambda) v=0
$$

With $\mathrm{I}$ is an identity matrix. Equation (2.8) has a nonzero solution which if only if, det $(A-I \lambda) v=0$ is called the characteristic equation of $\mathrm{A}$.

equilibrium point stability $\left(\mathrm{x}_{0}, \mathrm{y}_{0}\right)$ is divided into three, namely as follows [9]:

a. the equilibrium point $\left(\mathrm{x}_{0}, \mathrm{y}_{0}\right)$ is said to be asymptotically stable if $\lambda_{\mathrm{i}}<0$

b. equilibrium point $\left(\mathrm{x}_{0}, \mathrm{y}_{0}\right)$ is said to be stable if $\lambda_{\mathrm{i}}=0$.

c. the equilibrium point $\left.\left(\mathrm{x}_{0}, \mathrm{y}_{0}\right)\right)$ is said to be unstable if $\lambda_{\mathrm{i}}>0$. 


\section{Non homogeneous system solutions}

Given a non homogeneous system

$$
\dot{x}=A x+b(t)
$$

With A the matrix $\mathrm{n} \times \mathrm{n}$ and $\mathrm{b}(\mathrm{t})$ are vectors whose elements are continuous functions.

Definition: [10]

The fundamental solution matrix for the system

$$
\dot{X}=A x
$$

Is the matrix $\phi(\mathrm{t})$ measuring $\mathrm{n} \times \mathrm{n}$ that satisfies

For each $t \in R$

$$
\dot{\phi}(t)=A \phi(t)
$$

With the matrix $\phi(t)=e^{A t}$ satisfies equation (7) with the initial value $\phi(0)=I$, so that $\phi(t)=e^{A t}$ is called the fundamental matrix.

Theme: [10]

If $\phi(t)$ and $\psi$ are two fundamental solution matrices for the system (6) then there is a constant matrix C so that $\phi(t)=\psi(t) C$

Theorem: [10]

If $\phi(t)$ is the fundamental solution matrix of the system (6) then

Theorem: [10]

$$
e^{A t}=\psi(t) \psi^{-1}(0)
$$

If $\phi(t)$ is the fundamental matrix for the system (6) then the solution of the non homogeneous system (5) with the initial value is $X(0)$

$$
X(t)=\phi(t) \phi^{-1}(0) X(0)+\phi(t) \int_{0}^{t} \phi^{-1}(s) B d s
$$

\section{Fuzzy prey predator model}

Predator prey models with fuzzy initial conditions in linear form are given [6]

$$
\dot{X}=C X+B
$$

The solution to equation (8) is

Or it can be written

$$
\tilde{X}(t)=\psi(t) \psi^{-1}(0) \tilde{X}(0)+\psi(t) \int_{0}^{t} \psi^{-1}(s) B
$$

With $X(0)=\tilde{X}_{0}$ and $Y(0)=\tilde{Y}_{0}$

$$
[\bar{X}, \underline{X}]=\psi(t) \psi^{-1}(0)\left[\bar{X}_{0}, \underline{X}_{0}\right]+\psi(t) \int_{0}^{t} \psi^{-1}(s) B
$$

\section{Model Fixed Point Analysis}

To analyze the fixed point on the equation (1) that is by way of making $\frac{d N}{d t}=0, \frac{d P}{d t}=0$ and $\frac{d Q}{d t}=0$ so that equation (1) can be written as

$$
0=r N\left(1-\frac{N}{K}\right)-\alpha P N-\varphi Q N
$$




$$
\begin{aligned}
& 0=-c P+\beta N P \\
& 0=-e Q+\gamma N Q
\end{aligned}
$$

When $\frac{d N}{d t}=0$, then in equation (12) is obtained

$$
\begin{gathered}
-c P+\beta N P=0 \\
P \neq 0 \text { or }-c P+\beta N=0 \\
N=\frac{c}{\beta}
\end{gathered}
$$

When $\frac{d N}{d t}=0$, then in equation (13) is obtained

$$
\begin{array}{r}
-e Q+\gamma N Q=0 \\
Q \neq 0 \text { or }-e+\gamma N=0 \\
N=\frac{e}{\gamma}
\end{array}
$$

Whereas in equation (11) when $\frac{d Q}{d t}=0$, it is obtained

$$
\begin{array}{r}
r N\left(1-\frac{N}{K}\right)-\alpha P N-\varphi Q N=0 \\
N \neq 0 \text { atau } r\left(1-\frac{N}{K}\right)-\alpha P-\varphi Q=0
\end{array}
$$

If $\mathrm{N}=0, \mathrm{P}=0$ is substituted in equation (16) then obtained

$$
\begin{array}{r}
r-\varphi Q=0 \\
Q=\frac{r}{\varphi}
\end{array}
$$

If $\mathrm{N}=0, \mathrm{Q}=0$ is substituted in equation (16) then obtained

$$
\begin{array}{r}
r-\alpha P=0 \\
P=\frac{r}{\alpha}
\end{array}
$$

In equation (17) and (18) do not fulfill because in equation (16) the condition is $\mathrm{N} \neq 0$. The first fixed point is $\mathrm{TE}_{1}=(0,0,0)$

Whereas if $P=0$ and $Q=0$ are substituted in equation (16) then obtained

$$
\begin{gathered}
r\left(1-\frac{N}{K}\right)=0 \\
r \neq 0 \text { atau } 1-\frac{N}{K}=0 \\
N=K
\end{gathered}
$$

So that the second fixed point is obtained $T E_{2}=(K, 0,0)$ 
If $N=\frac{c}{\beta}, Q=0$ is substituted in equation (16) then obtained

So $T E_{3}=\left(\frac{c}{\beta}, \frac{1}{\alpha}\left(r-\frac{r c}{\beta K}\right), 0\right)$

$$
\begin{aligned}
r\left(1-\frac{N}{K}\right)-\alpha P-\varphi Q & =0 \\
\frac{1}{\alpha}\left(r-\frac{r C}{\beta K}\right) & =P
\end{aligned}
$$

For the fourth fixed point, substitute $N=\frac{e}{\gamma}$ and $\mathrm{P}=0$ in equation (16) so that it is obtained

So $T E_{4}=\left(\frac{e}{\gamma}, 0, \frac{1}{\varphi}\left(r-\frac{r e}{\gamma K}\right)\right)$

$$
\begin{array}{r}
r\left(1-\frac{N}{K}\right)-\alpha P-\varphi Q=0 \\
\frac{1}{\varphi}\left(r-\frac{r e}{\gamma K}\right)=Q
\end{array}
$$

For the fifth fixed point of substitution $N=\frac{C}{\beta}, Q=Q^{*}$ in equation (16) is obtained

$$
\begin{gathered}
r\left(1-\frac{N}{K}\right)-\alpha P-\varphi Q=0 \\
\frac{1}{\alpha}\left(r-\frac{r c}{\beta K}-\varphi Q^{*}\right)=P
\end{gathered}
$$

So $T E_{5}=\left(\frac{C}{\beta}, \frac{1}{\alpha}\left(r-\frac{r c}{\beta K}-\varphi Q^{*}\right), Q^{*}\right)$

If $N=\frac{e}{\gamma}$ and $Q=Q^{*}$ are substituted in equation (15) obtained

$$
\begin{gathered}
r\left(1-\frac{N}{K}\right)-\alpha P-\varphi Q=0 \\
\frac{1}{\alpha}\left(r-\frac{r e}{\gamma K}-\varphi Q^{*}\right)=P
\end{gathered}
$$

So $T E_{6}=\left(\frac{e}{\gamma}, \frac{1}{\alpha}\left(r-\frac{r e}{\gamma K}-\varphi Q^{*}\right), Q^{*}\right)$

Substitute $N=\frac{C}{\beta}, P=P^{*}$ in equation (16) then obtained

$$
\begin{aligned}
r\left(1-\frac{N}{K}\right)-\alpha P-\varphi Q & =0 \\
\frac{1}{\varphi}\left(r-\frac{r c}{\beta K}-\alpha P^{*}\right) & =Q
\end{aligned}
$$

So $T E_{7}=\left(\frac{C}{\beta}, P^{*}, \frac{1}{\varphi}\left(r-\frac{r c}{\beta K}-\alpha P^{*}\right)\right)$

If $N=\frac{e}{\gamma}$ and $P=P^{*}$ are substituted in equation (16) obtained

$$
\begin{aligned}
& r\left(1-\frac{N}{K}\right)-\alpha P-\varphi Q=0 \\
& \frac{1}{\varphi}\left(r-\frac{r e}{\gamma K}-\alpha P^{*}\right)=Q \\
& \text { So } T E_{8}=\left(\frac{e}{\gamma}, P^{*}, \frac{1}{\varphi}\left(r-\frac{r e}{\gamma K}-\alpha P^{*}\right)\right)
\end{aligned}
$$

\section{Linearization}

Linearization is the process of linearizing nonlinear functions. from equation (1) suppose a function can be written as follows:

For example:

$$
: \dot{N}=f_{1}(N, P, Q)
$$




$$
\dot{P}=f_{2}(N, P, Q,)
$$

$$
\dot{Q}=f_{3}(N, P, Q,)
$$

So that from equations (19), (20) and (21) by using a Taylor series, the blue matrix is obtained as follows:

$$
\left[\begin{array}{l}
\dot{N} \\
\dot{P} \\
\dot{Q}
\end{array}\right]=\left[\begin{array}{lll}
\frac{\partial f_{1}}{\partial N} & \frac{\partial f_{1}}{\partial P} & \frac{\partial f_{1}}{\partial Q} \\
\frac{\partial f_{2}}{\partial N} & \frac{\partial f_{2}}{\partial P} & \frac{\partial f_{2}}{\partial Q} \\
\frac{\partial f_{3}}{\partial N} & \frac{\partial f_{3}}{\partial P} & \frac{\partial f_{3}}{\partial Q}
\end{array}\right]\left[\begin{array}{l}
N \\
P \\
Q
\end{array}\right]
$$

From the equation ( 22) the Jacobic matrix is obtained as follows:

$$
\left[\begin{array}{c}
\dot{N} \\
\dot{P} \\
\dot{Q}
\end{array}\right]=\left[\begin{array}{ccc}
r-\frac{2 r N}{K}-\alpha P-\varphi Q & -\alpha N & -\varphi N \\
\beta P & -c+\beta N & 0 \\
\gamma Q & 0 & -e+\gamma N
\end{array}\right]\left[\begin{array}{l}
N \\
P \\
Q
\end{array}\right]
$$

So that based on equation (23) is obtained:

$$
A=\left[\begin{array}{ccc}
r-\frac{2 r N}{K}-\alpha P-\varphi Q & -\alpha N & -\varphi N \\
\beta P & -c+\beta N & 0 \\
\gamma Q & 0 & -e+\gamma N
\end{array}\right]
$$

\section{Stability}

At this stage the eigenvalue of equation (23) will be searched as follows

$$
|\lambda I-A|
$$

Then obtained

$$
\left|\left[\begin{array}{ccc}
\lambda-r+\frac{2 r N}{K}+\alpha P+\varphi Q & \alpha N & \varphi N \\
-\beta P & \lambda+c-\beta N & 0 \\
-\gamma Q & 0 & \lambda+e-\gamma N
\end{array}\right]\right|=0
$$

Furthermore, from equation (25), the determinant will be obtained as follows

$$
\begin{aligned}
& \lambda^{3}+\lambda^{2}\left(e-\gamma N+c-\beta N-r+\frac{2 r N}{K}+\alpha P+\varphi Q\right)+\lambda\left(c e-c \gamma N-\beta e N+\beta \gamma N^{2}-e r+\right. \\
& \gamma r N-c r+\beta r N+\frac{2 r e N}{K}-\frac{2 \gamma r N^{2}}{K}+\frac{2 c r N}{K}-\frac{2 \beta r N^{2}}{K}+e \alpha P-\gamma \alpha N P+c \alpha P+e \varphi Q+c \varphi Q- \\
& \beta \varphi N Q)+\left(-c e r+c \gamma r N+\beta e r N-\beta \gamma r N^{2}+\frac{2 c e r N}{K}-\frac{2 c \gamma r N^{2}}{K}-\frac{2 \beta e r N^{2}}{K}+\frac{2 \beta r \gamma N^{3}}{K}+c e \alpha P-\right. \\
& c \gamma \alpha N P+c e \varphi Q-\beta e N Q)=0
\end{aligned}
$$

The parameter calculation of equation (1) is as follows

$$
\begin{aligned}
r & =\frac{\sum \text { terkonfirmasi }}{\text { total }} \\
& =\frac{150}{295} \\
& =0,373 \\
K & =\frac{\sum \text { fot torak tidak dilakukan }}{\text { total }} \\
& =\frac{245}{295} \\
& =0,831
\end{aligned}
$$




$$
\begin{aligned}
& c=\frac{\sum \text { fot torak tidak dilakukan bakteriologis }}{\text { total }} \\
& =\frac{113}{295} \\
& =0,383 \\
& e=\frac{\sum \text { fot torak tidak dilakukan terdiagnosis klinis }}{\text { total }} \\
& =\frac{35}{295} \\
& =0,119 \\
& \alpha=\left(\frac{\sum \text { M.positif bakteriologis }}{\text { total }}\right)\left(\frac{\text { bakteriologis }}{\text { total }}\right) \\
& =\left(\frac{117}{295}\right)\left(\frac{126}{\text { total }}\right) \\
& =0,170 \\
& \beta=\left(\frac{\sum M . \text { positif bakteriologis }}{\text { total }}\right)\left(\frac{\text { terkonfirmasi }}{\text { total }}\right) \\
& =\left(\frac{117}{295}\right)\left(\frac{150}{\text { total }}\right) \\
& =0,148 \\
& \varphi=\left(\frac{\sum M . \text { positif terdiagnosis klinis }}{\text { total }}\right)\left(\frac{\text { terdiagnosis klinis }}{\text { total }}\right) \\
& =\left(\frac{21}{295}\right)\left(\frac{60}{\text { total }}\right) \\
& =0,014 \\
& \gamma=\left(\frac{\sum M . \text { positif terdiagnosis klinis }}{\text { total }}\right)\left(\frac{\text { terkonfirmasi }}{\text { total }}\right) \\
& =\left(\frac{21}{295}\right)\left(\frac{150}{\text { total }}\right) \\
& =0,026
\end{aligned}
$$

Based on these parameter values, a prey predator model with two predators is obtained

$$
\begin{aligned}
& \frac{d N}{d t}=0,373 N\left(1-\frac{N}{0,831}\right)-0,170 P N-0,014 Q N \\
& \frac{d P}{d t}=-0,383 P+0,148 N P \\
& \frac{d Q}{d t}=-0,119 Q+0,026 N Q
\end{aligned}
$$

Furthermore, the values of these parameters are substituted at the known fixed points as follows

For the first fixed point obtained:

$$
T E_{1}=(0,0,0)
$$

For the second fixed point:

$$
\begin{aligned}
& T E_{2}=(K, 0,0) \\
& =(0,831 ; 0)
\end{aligned}
$$

For the third fixed point obtained

$$
\begin{aligned}
T E_{3} & =\left(\frac{c}{\beta} ; \frac{1}{\alpha}\left(r-\frac{r c}{\beta K}\right) ; 0\right) \\
& =(2,588 ;-7,93 ; 0)
\end{aligned}
$$

For the fourth fixed point obtained: 
(33)

$$
\begin{aligned}
T E_{4} & =\left(\frac{e}{\gamma} ; 0 ; \frac{1}{\varphi}\left(r-\frac{r e}{\gamma K}\right)\right) \\
& =(4,577 ; 0 ;-110)
\end{aligned}
$$

For the fifth fixed point obtained:

$$
\begin{aligned}
T E_{5}=\left(\frac{c}{\beta} ; \frac{1}{\alpha}\left(r-\frac{r c}{\beta K}-\varphi Q^{*}\right) ; Q^{*}\right) \\
\quad=\left(2,588 ;-4,647-0,082 Q^{*} ; Q^{*}\right)
\end{aligned}
$$

For the sixth fixed point obtained:

$$
\begin{aligned}
T E_{6}=\left(\frac{e}{\gamma} ; \frac{1}{\alpha}\left(r-\frac{r e}{\gamma K}-\varphi Q^{*}\right) ; Q^{*}\right) \\
\quad=\left(4,577 ;-9,571-0,082 Q^{*} ; Q^{*}\right)
\end{aligned}
$$

For the seventh fixed point obtained:

$$
\begin{aligned}
T E_{7}= & \left(\frac{c}{\beta} ; P^{*} ; \frac{1}{\varphi}\left(r-\frac{r c}{\beta K}-\alpha P^{*}\right)\right) \\
& =\left(2,588 ; P^{*} ;-56,429-12,143 P^{*}\right)
\end{aligned}
$$

For the eighth fixed point obtained:

$$
\begin{aligned}
T E_{8} & =\left(\frac{e}{\gamma} ; P^{*} ; \frac{1}{\varphi}\left(r-\frac{r e}{\gamma K}-\alpha P^{*}\right)\right) \\
& =\left(4,577 ; P^{*} ;-116,214-12,143 P^{*}\right)
\end{aligned}
$$

Furthermore, to find out the stability of the fixed point, the fixed point value of equation (30) and the parameters are substituted in equation (26) so that it is obtained

$$
\lambda^{3}+0,129 \lambda^{2}-0,141 \lambda-0,017=0
$$

So the lamda value of equation (38) is $\lambda_{1}=0,3723 ; \lambda_{2}=-0,3817$ dan $\lambda_{3}=-0,1196$ Furthermore, to determine the stability of the fixed point, the fixed point value of equation (31) and the parameters are substituted in equation (26) so that it is obtained

$$
\lambda^{3}+0,729 \lambda^{2}-0,16 \lambda-0,013=0
$$

So the lamda value of equation (39) is $\lambda_{1}=-0,4239 ; \lambda_{2}=-0,1526$ dan $\lambda_{3}=-0,1526$ To find out the stability of the fixed point, the fixed point value of equation (32) and the parameters are substituted in equation (26) so that it is obtained

$$
\lambda^{3}+0,654 \lambda^{2}-0,484 \lambda-0,015=0
$$

So the lamda value of equation (40) is $\lambda_{1}=-1,1045 ; \lambda_{2}=0,4180$ dan $\lambda_{3}=0,0325$

Furthermore, to determine the stability of the fixed point, the fixed point value of equation (33) and the parameters are substituted in equation (26) so that it is obtained

$$
\lambda^{3}+1,902 \lambda^{2}-0,829 \lambda+8,926=0
$$

So the lamda value of equation (41) is $\lambda_{1}=-3,0990 ; \lambda_{2}=0,5985$ dan $\lambda_{3}=0,5985$ Furthermore, to determine the stability of the fixed point, the fixed point value of equation (34) and the parameters are substituted in equation (26) so that it is obtained

$$
\lambda^{3}+1,212 \lambda^{2}+\left(-0,147-0,004 Q^{*}\right) \lambda+\left(0,12-0,044 Q^{*}\right)=0
$$

If $Q^{*}=2$, the lamda value of equation (42) is $\lambda_{1}=-1,3449 \lambda_{2}=0,0665$; and $\lambda_{3}=$ 0,0665 , and if $Q^{*}=3$, the lamda value of equation (42) is $\lambda_{1}=-1,3252 ; \lambda_{2}=0,1673$ dan $\lambda_{3}=-0,054$ 
Furthermore, to determine the stability of the fixed point, the fixed point value of equation (35) and the parameters are substituted in equation (26) so that it is obtained

$$
1,815 \lambda^{2}+\left(-1,721-0,007 Q^{*}\right) \lambda+\left(0,129-0,08 Q^{*}\right)=0
$$

If $Q^{*}=2$, the lamda value of equation (43) is $\lambda_{1}=-2,5032 ; \lambda_{2}=0,7057$; and $\lambda_{3}=$ $-0,0175$ and if $Q^{*}=5$ then the lamda value of equation (43) is $\lambda_{1}=-2,4792 ; \lambda_{2}=$ 0,8007 dan $\lambda_{3}=-0,0601$.

Furthermore, to determine the stability of the fixed point, the fixed point value of equation (36) and the parameters are substituted in equation (26) so that it is obtained

$$
\lambda^{3}+1,212 \lambda^{2}+\left(0,084+0,05 P^{*}\right) \lambda+\left(2,581+0,551 P^{*}\right)=0
$$

If $P^{*}=2$, the lamda value of equation (44) is $\lambda_{1}=-2,0219 ; \lambda_{2}=0,4050$ dan $\lambda_{3}=$ 0,4050

Furthermore, to determine the stability of the fixed point, the fixed point value of equation (37) and the parameters are substituted in equation (26) so that it is obtained

$$
\lambda^{3}+1,212 \lambda^{2}+\left(0,084+0,05 P^{*}\right) \lambda+\left(2,581+0,551 P^{*}\right)=0
$$

If $P^{*}=2$, the lamda value of equation (45) is $\lambda_{1}=-3,1664 ; \lambda_{2}=0,6757$ dan $\lambda_{3}=0,6757$

\section{Application of Fuzzy Based Prey Predator Model}

Substitute fixed points $\mathrm{N}=4,577$ in equation (27) so that they are obtain

$$
\dot{N}=0,373(4,577)\left(1-\frac{4,577}{0,831}\right)-0,170(4,577) P-0,014(4,577) Q
$$

Can be simplified to be

$$
\dot{N}=-7,6958482142-0,77809 P-0,064078 Q
$$

Subsequently the substitution of fixed points $\mathrm{P}=-9,981$ in equation (28) follows

Can be simplified to be

$$
\dot{P}=-0,383(-9,981)+0,148(-9,981) N
$$

$$
\dot{P}=3,822723-1,477188 N
$$

Furthermore, substitution of fixed points $Q=5$ in equation (29) follows

Can be simplified to be

$$
\dot{Q}=-0,119(5)+0,026(5) N
$$

$$
\dot{Q}=-0,595+0,13 N
$$

From equations (46), (47) and (48) can be made a $C$ matrix measuring $3 \times 3$ and vector B measuring $3 \times 1$ as follows:

$$
C=\left[\begin{array}{ccc}
0 & -0,77809 & -0,064078 \\
-1,477188 & 0 & 0 \\
0,13 & 0 & 0
\end{array}\right] \text { and } B=\left[\begin{array}{c}
-7,6958482142 \\
3,822723 \\
-0,595
\end{array}\right]
$$

By using menggunakan $\lambda_{1}=-2,4792$ the eigenvectors will be searched from the $\mathrm{C}$ matrix as follows: $\left(\lambda_{1}-A\right) x=0$

$$
\left[-2,4792\left[\begin{array}{lll}
1 & 0 & 0 \\
0 & 1 & 0 \\
0 & 0 & 1
\end{array}\right]-\left[\begin{array}{ccc}
0 & -0,77809 & -0,064078 \\
-1,477188 & 0 & 0 \\
0,13 & 0 & 0
\end{array}\right]\right]\left[\begin{array}{l}
N \\
P \\
Q
\end{array}\right]=\left[\begin{array}{l}
0 \\
0 \\
0
\end{array}\right]
$$




$$
\begin{array}{r}
{\left[\begin{array}{ccc}
-2,4792 & 0 & 0 \\
0 & -2,4792 & 0 \\
0 & 0 & -2,4792
\end{array}\right]-\left[\begin{array}{ccc}
0 & -0,77809 & -0,064078 \\
-1,477188 & 0 & 0 \\
0,13 & 0 & 0
\end{array}\right]\left[\begin{array}{l}
N \\
P \\
Q
\end{array}\right]=\left[\begin{array}{l}
0 \\
0 \\
0
\end{array}\right]} \\
{\left[\begin{array}{cccc}
-2,4792 & 0,77809 & 0,064078 \\
1,477188 & -2,4792 & 0 \\
-0,13 & 0 & -2,4792
\end{array}\right]\left[\begin{array}{l}
N \\
P \\
Q
\end{array}\right]=\left[\begin{array}{l}
0 \\
0 \\
0
\end{array}\right]}
\end{array}
$$

Can be written to be

$$
\begin{aligned}
& -2,4792 N+0,77809 P+0,064078 Q=0 \\
& 1,477188 N-2,4792 P=0 \\
& -0,13 N-2,4792 Q=0
\end{aligned}
$$

So the eigenvector of equation (49) is

$$
\begin{aligned}
-2,4792 N+0,77809 P+0,064078 Q & =0 \\
0,064078 Q & =2,4792 N-0,77809 P \\
Q & =\frac{2,4792 N-0,77809 P}{0,064078} \\
{\left[\begin{array}{c}
1 \\
1 \\
26,5474889978
\end{array}\right] } &
\end{aligned}
$$

For the eigenvector of equation (50) it is obtained

$$
\begin{aligned}
1,477188 N-2,4792 P & =0 \\
-2,4792 P & =-1,477188 N \\
& P=\frac{-1,477188 N}{-2,4792} \\
{\left[\begin{array}{c}
1 \\
0,5958325266 \\
0
\end{array}\right] } &
\end{aligned}
$$

For the eigenvector of equation (51) it is obtained

$$
\begin{aligned}
& -0,13 N-2,4792 Q=0 \\
& -2,4792 Q=0,13 N \\
& Q=\frac{0,13 N}{-2,4792} \\
& {\left[\begin{array}{c}
1 \\
0 \\
-0,0524362698
\end{array}\right]}
\end{aligned}
$$

From the known eigenvectors, the fundamental matrix is obtained as follows:

$$
\psi(t)=\left[\begin{array}{ccc}
e^{-2,4792 t} & e^{-2,4792 t} & e^{-2,4792 t} \\
e^{-2,4792 t} & 0,5958325266 e^{-2,4792 t} & 0 \\
26,5474889978 e^{-2,4792 t} & 0 & -0,0524362698 e^{-2,4792 t}
\end{array}\right]
$$

Substitute equation (52) in equation (9) as follows

$$
X(t)=\psi(t) \psi^{-1}(0) X(0)+\psi(t) \int_{0}^{t} \psi^{-1}(s) B d s
$$

Then obtained 


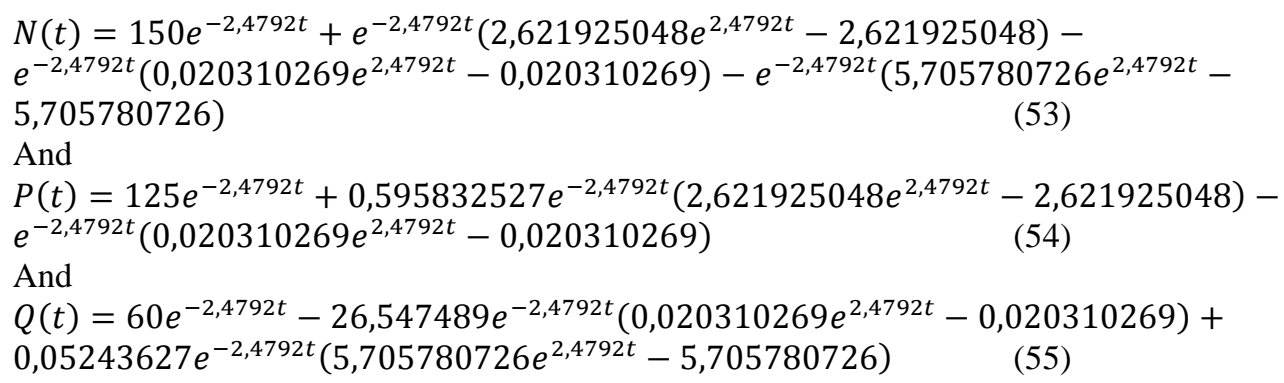

And

$P(t)=125 e^{-2,4792 t}+0,595832527 e^{-2,4792 t}\left(2,621925048 e^{2,4792 t}-2,621925048\right)-$ $e^{-2,4792 t}\left(0,020310269 e^{2,4792 t}-0,020310269\right)$

And

$Q(t)=60 e^{-2,4792 t}-26,547489 e^{-2,4792 t}\left(0,020310269 e^{2,4792 t}-0,020310269\right)+$ $0,05243627 e^{-2,4792 t}\left(5,705780726 e^{2,4792 t}-5,705780726\right)$

From equation (53), (54) and equation (55) by using MATLAB R2015a software, Graph 1 is obtained as follows:

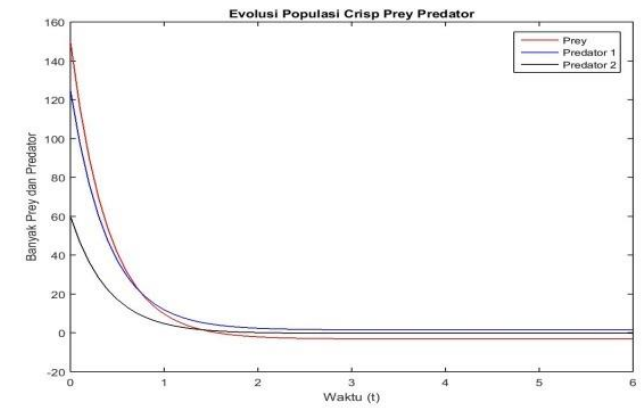

Fig. 1. Population of Crisp Prey Predator

In Figure 1 it can be explained that the population population and predator population both decreased for one month after it was convergent.

\section{Application of Fuzzy Initial Value to Prey Predator Models}

By substituting the initial values for triangular fuzzy numbers, it is obtained

$$
\begin{gathered}
\widetilde{N_{0}}= \begin{cases}\frac{x-110}{40}, & 110<x \leq 150 \\
\frac{170-x}{20}, & 150<x \leq 170\end{cases} \\
\widetilde{P_{0}}= \begin{cases}\frac{x-85}{40}, & 85<x \leq 125 \\
\frac{145-x}{20}, & 125<x \leq 145\end{cases} \\
\widetilde{Q_{0}}=\left\{\begin{array}{l}
\frac{x-20}{40}, 20<x \leq 60 \\
\frac{80-x}{20}, 60<x \leq 80
\end{array}\right. \\
\left(\widetilde{N}_{0}\right)^{\alpha}=[40 \alpha+110,170-20 \alpha] \\
\left(\widetilde{P}_{0}\right)^{\alpha}=[40 \alpha+85,145-20 \alpha] \\
\left(\widetilde{Q}_{0}\right)^{\alpha}=[40 \alpha+20,80-20 \alpha]
\end{gathered}
$$

So $\overline{X_{0}}=\left[\begin{array}{c}170 \\ 145 \\ 80\end{array}\right]$ and $\underline{X}_{0}=\left[\begin{array}{c}110 \\ 85 \\ 20\end{array}\right]$ 
Then by using $\overline{X_{0}}=\left[\begin{array}{c}170 \\ 145 \\ 80\end{array}\right]$ in equation (10) then it is obtained

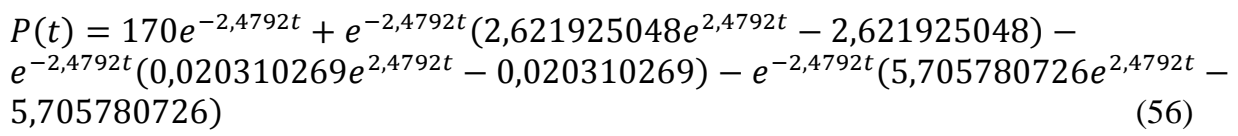

And

$P(t)=145 e^{-2,4792 t}+0,595832527 e^{-2,4792 t}\left(2,621925048 e^{2,4792 t}-2,621925048\right)-$ $e^{-2,4792 t}\left(0,020310269 e^{2,4792 t}-0,020310269\right)$

And

$Q(t)=80 e^{-2,4792 t}-26,547489 e^{-2,4792 t}\left(0,020310269 e^{2,4792 t}-0,020310269\right)+$ $0,05243627 e^{-2,4792 t}\left(5,705780726 e^{2,4792 t}-5,705780726\right)$

From equations (56), (57) and equations (58), using MATLAB R2015a software, Graph 2 is obtained as follows:

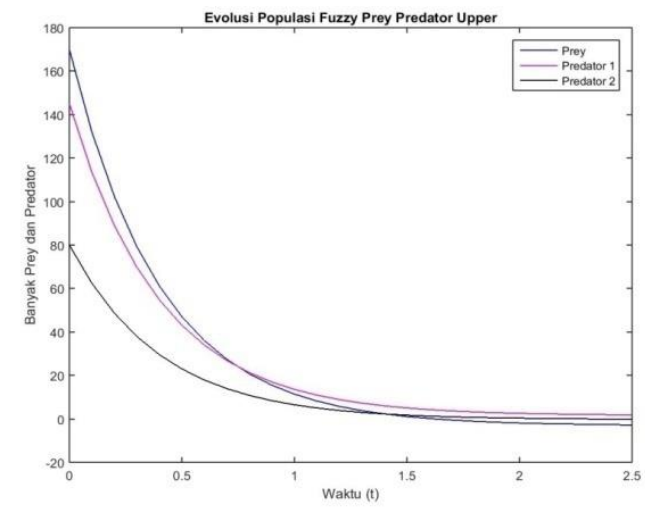

Fig. 2. Fuzzy Population Prey upper predator 
In Figure 2, it can be explained that the fuzzy population prey predator uppuer is convergent. For $\underline{X_{0}}=\left[\begin{array}{c}110 \\ 85 \\ 20\end{array}\right]$ it is referred to in equation (10) then obtained

$N(t)=110 e^{-2,4792}+e^{-2,4792}\left(2,621925048 e^{2,4792}-2,621925048\right)-$ $e^{-2,4792}\left(0,020310269 e^{2,4792}-0,020310269\right)-e^{-2,4792}\left(5,705780726 e^{2,4792}-\right.$

$5,705780726)$

And

$P(t)=85 e^{-2,4792}+0,595832527 e^{-2,4792}\left(2,621925048 e^{2,4792}-2,621925048\right)-$ $e^{-2,4792}\left(0,020310269 e^{2,4792}-0,020310269\right)$

And

$Q(t)=20 e^{-2,4792}-26,547489 e^{-2,4792}\left(0,020310269 e^{2,4792}-0,020310269\right)+$

$0,05243627 e^{-2,4792}\left(5,705780726 e^{2,4792}-5,705780726\right)$

From equations (59), (60) and equations (61) then using MATLAB R2015a software is obtained in Graph 3 as follows:

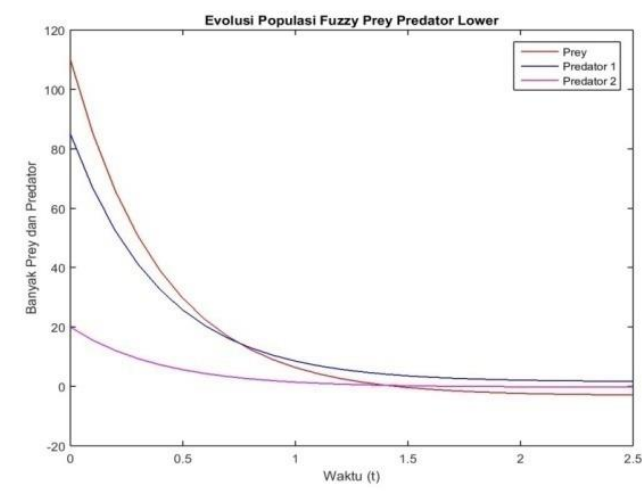

Fig. 3. Lower lower Fuzzy prey Predator population

In Figure 3, it can be explained that fuzzy prey populations are lower converging predators. Prey upper and prey lowe combined results can be seen in graph 4 as follows:

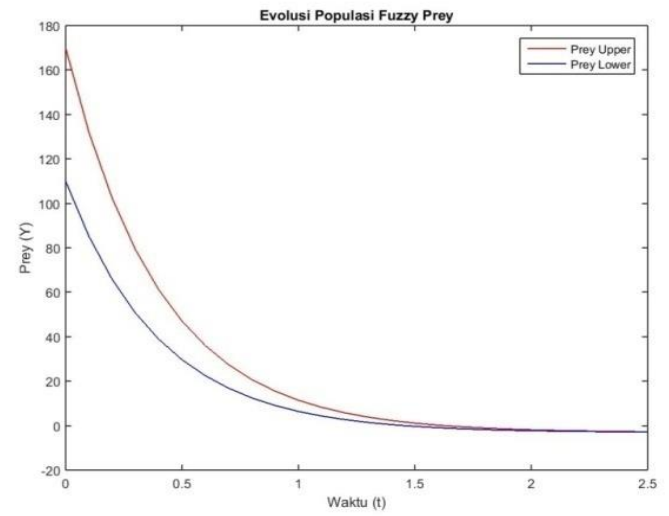

Fig. 4. The prey upper and lower prey populations proved convergent 
The combined results of the first upper predator and first predator can be seen in graph 5 as follows:

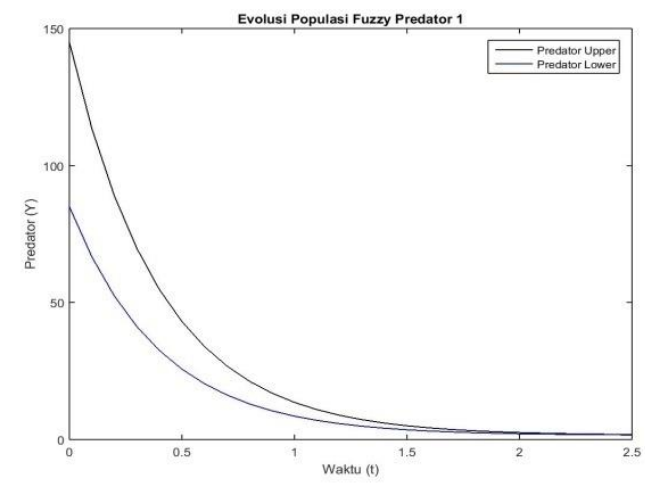

Figure 5 The first Fuzzy population predator

In figure 5 it can be explained that the upper first predator population and the first lower predator proved convergent.

The combined results of the second upper and second predator lowe can be seen in graph 6 as follows:

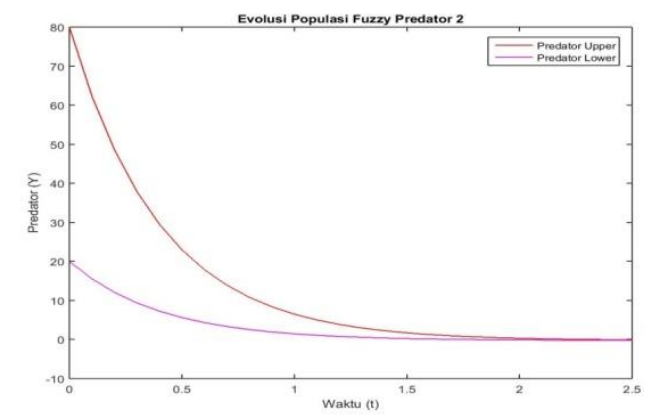

Figure 6 Second Population Fuzzy Predator

In figure 6 it can be explained that the upper first predator population and the first lower predator proved convergent.

\section{Conclude}

Based on the simulation results using the Fuzzy Prey Predator method, the conclusion is that the population of Prey and Predator is stable, so that after applying the Fuzzy Prey Predator model, convergent results are obtained. Prey population and Predator population have declined for one month, after that covergen ..

\section{Acknowledgments}

The author would like to thank:

1. Ristekdikti who have provided funding assistance related to PKM PE.

2. Dean, study program MIPA UIM and Supervisor who have succeeded PKM PE.

3. The Batumarmar health center has helped in the completion of PKM PE. 


\section{References}

[1] E. Novita and Z. Ismah, "Studi Karakteristik Pasien Tuberculosis di Puskesmas Seberang," Unnes J. Public Heal., p. 219, 2017.

[2] H. Mulyanto, "Lima Indikator Perilaku Hidup Bersih dan Sehat,” p. 356, 2014.

[3] Dinas Kesehatan Jawa Timur, Profil Provinsi Jawa Timur. Surabaya: Dinas Kesehatan Provinsi Jawa Timur. Surabaya: Dinas Kesehatan Provinsi Jawa Timur, 2016.

[4] B. Budiono, 6 Bulan, 230 Kasus TBC di Pamekasa. Pamekasan: Compas.com., 2011.

[5] Dinas Kesehatan Pamekasan, Profil Kesehatan Kabupaten Pamekasan. Pamekasan: Dinas Kesehatan Kabupaten Pamekasan, 2014.

[6] M. d. Peixoto, L. C. Barros, and R. C. Bassanezi, "Predator-prey fuzzy model," Ecol. Modell., vol. 214, pp. 39-44, 2008.

[7] T. Yulianto, S. Komariyah, and N. Ulfaniyah, "Application of fuzzy inference system by Sugeno method on estimating of salt production," in AIP Conference Proceedings, 2017, pp. 020039-1.

[8] Didiharyono, “Analisis Kestabilan dan Keuntungan Maksimum Model Predator-Prey Fungsi Respon Tipe Holling III dengan Usaha Pemanenan,” J. Masagena, p. 318, 2016.

[9] Jamaluddin, "Analisis Titik Setimbang dan Kestabilan Model Matematika pada Penyakit Hepatitis C (HCV) dengan MMT," Universitas Islam Madura, 2015.

[10] K. P. Krisnawan, Sistem Linier Nonhomogen. Yogyakarta: Mathematics Department Yogyakarta State University, 2012. 